\title{
Comparative Study of P\&O and Fuzzy MPPT Controllers and Their Optimization Using PSO and GA to Improve Wind Energy System
}

\author{
Abdelhalim Borni(1), Mohcene Bechouat ${ }^{(2)}$, Noureddine Bessous( ${ }^{(3)}$, Abdelhak \\ Bouchakour(1), Zarour Laid(4), Layachi Zaghba(1) $^{(1)}$
}

(1) Unité de Recherche Appliquée en Energies Renouvelables, URAER, Centre de Développement des Energies Renouvelables, CDER, 47133, Ghardaïa, ALGERIA

e-mails: borniabdelhalim77@gmail.com; abdelhakuraer@gmail.com; layachi40@yahoo.fr

(2) Faculty of Science and Technology, University of Ghardaïa, ALGERIA

e-mail:mohcene.oui@gmail.com

(3) Department of Electrical Engineering University of El Oued, Fac. Technology, El-Oued 39000, ALGERIA e-mail: bessous-noureddine@univ-eloued.dz

(4) Department of Electrical Engineering, Laboratory of Electrical, Constantine (LEC), Brother Mentoury University, ALGERIA e-mail: laidzarour@hotmail.fr

\section{SUMMARY}

Many academics have recently focused on wind energy installations. WECS (wind energy conversion system) is a renewable energy source that has seen significant development in recent years. Furthermore, compared to the use of power grid supply, the use of the WECS in the water pumping field is a cost-free option (economically). The purpose of this study is to demonstrate a wind-powered pumping mechanism. To obtain the best option, it considers and contrasts four distinct approaches. This research aims to improve the system's performance and the quality of the generated power. The objective of the control of WECS with a permanent magnet synchronous generator (PMSG) is to carefully maximize power generation. Finally, this research employed the fuzzy logic control (FLC) and particle swarm optimization (PSO) algorithms improved using a genetic algorithm (GA). The proposed system's performance was tested using the generated output voltage, current, and power waveforms, as well as the intermediate circuit voltage waveform and generator speed. The provided data show that the control technique used in this study was effective.

KEY WORDS: $\quad$ Wind energy; Fuzzy logic control; Maximum power point tracking (MPPT); Genetic algorithm (GA); Perturb and observe (P\&O); Particle swarm optimization (PSO). 


\section{INTRODUCTION}

Wind energy conversion systems (WECSs) have lately aroused interest of many academics [1]. Wind power contributes to the long-term maintenance of biodiversity in natural areas because of low hazard (100 percent natural) and large economic benefits (renewable and sustainable electricity).

Because solar systems (PVS) take up much space for a small amount of power, wind energy has the advantage of a greater output in the winter (the wind is generally stronger in the cold season). Due to greater energy consumption in the winter, the living expenses are higher [1,2], so this might become a significant benefit.

Water Pumping Systems (WPS) are used in a variety of applications (agriculture, domestic exploitation, etc.). As a result, the development of a dependable and efficient wind power system to address the issue of water shortage in arid locations is highly intriguing.

Alternative current (AC) motors are typically used in these systems, linked via a charge controller or inverter [3]. The induction motor utilized in the water pumping system was also employed in this research. Furthermore, permanent magnet synchronous generators (PMSGs) were utilized with WECS because of their compact size, self-excitation, high reliability, minimal maintenance, lack of a gearbox system, and low noise. [4, 5].

As a result, PMSG-Wind energy's maximum power point tracking (MPPT) was thoroughly validated. In the study, the maximum power point was verified using the perturb and observe (P\&O) approach. In this approach, the difference in output power between the present and prior system states is used to define system control. In its most basic form, P\&O used for MPPT has a set step size. Therefore, many academics have developed a variety of variable step MPPT techniques to address the issue $[6,7]$.

The control block techniques used to regulate the generator and the water pump utilizing a converter/inverter system are based on cascaded systems. The goal of the control approach based on traditional proportional-integral controllers (PICs) $[8,9]$ is to assure the system's resilience and stability. However, the high sensitivity of nonlinear systems and/or changing parameters make PICs challenging. The best and optimal PICs are known to be dependent on parameter estimations, specifically in electrical power systems $[8,9]$. This research includes a section on how to tackle the system's nonlinearity problem.

The FLC is the most essential component of this research as it has a different approach from PI control techniques to regulate the characteristics of nonlinear dynamic systems.

FLCs provide qualities, such as efficiency, while preserving the nonlinear system's dynamic properties. In general, the designer's expertise in membership functions determines the FLC (MF) $[10,11]$.

On the other hand, several conventional FLCs are based on a fixed MF and a static rule base, but this is insufficient to handle nonlinear systems with a high degree of uncertainty. As a result, adaptive filtering approaches based on Continuous Mixed-Normal algorithms were utilized (CMPN) to increase the performance of a wind generator linked to a water pump at variable speed, updating the FLC scale factors online $[6,12]$. This project presents a WECS that is linked to a water pump and has a decent MPPT.

The outline of the paper is as follows: P\&O technique alone, FLC non-optimized, FLC optimized by GA, and FLC optimized by PSO. 
Various FLC-based approaches described in this work are targeted at pursuing the optimal power point and increasing the efficiency of a WECS pumping system regardless of wind power variation. The FLC method reduced the measuring time, as presented in the findings. A comparison analysis enables maintaining a high level of accuracy and create a reliable controller.

\section{MODELING SYSTEM}

- This research focuses on the renewable energy system defined as the primary energy source by the WECS. WECS is connected to a water pumping system that uses an induction motor (IM). The essential parts of a hybrid system are shown in Figure 1, being:

- A PMSG Machine $(5.5 \mathrm{~kW})$;

- A static DC-DC converter for adapting the load to the PMSG and a DC-AC converter to couple to the IM (water pump) and the WECS;

- $\quad$ Two static converters, DC-DC, for adapting the load with WECS connected to the IM.

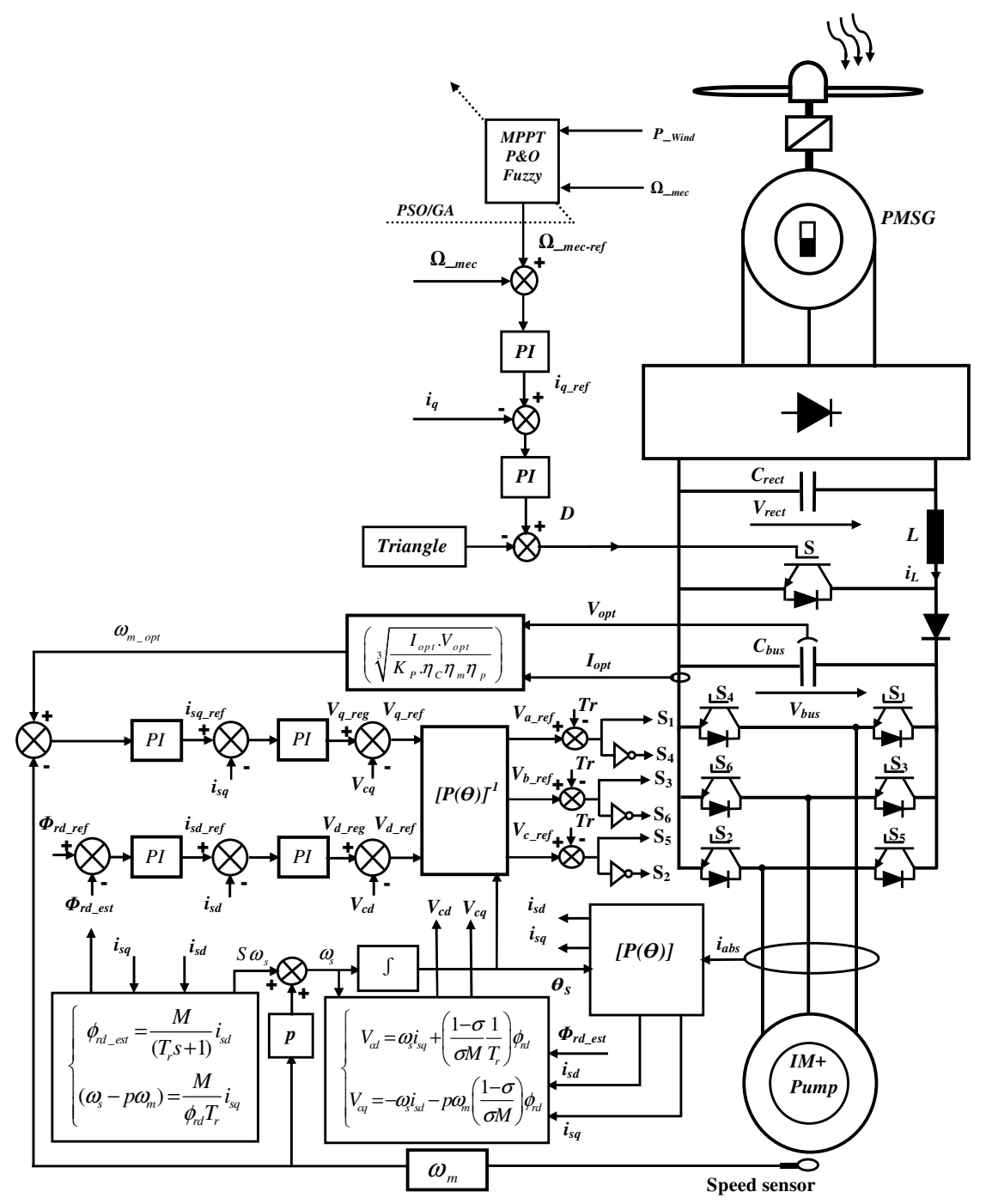

Fig. 1 Global diagram of WECS 
The FLC optimized for the WEC-PMSG system coupled to the water pump is developed using system modeling. The system concept consists of WECS, PMSG, two power converters connected back to back by a DC link capacitor, step-up transformer, and a dual circuit transmission line.

\subsection{TURBINE MODELLING}

The power value is determined by the mass of the air and its velocity $V_{w}[13,14]$.

$$
P_{w}=\frac{1}{2} \rho \cdot \pi \cdot R^{2} \cdot C_{p}(\lambda, \beta) \cdot V_{w}^{3}
$$

where:

$R$ is the blades of length and $K$ is the gain multiplier, $C_{p}$ is the value depending on the speed point ratio $(\lambda)$ and the blade step angle $(\beta)$ on the turbine characteristics (Figure 2(a)),

with:

$$
C p=0,5\left(\left(\frac{98}{\lambda^{\prime}}\right)-0,4 \beta-5\right) \exp \left(\frac{-16,5}{\lambda^{\prime}}\right)
$$

and

$$
\lambda^{\prime}=1 /\left(\frac{1}{\lambda+0,089}-\frac{0,035}{\lambda^{3}+1}\right) .
$$

$P_{w}=f(\Omega)$ is shown in Figure 2 for various wind speeds. Each curve depicts an optimal power point associated with a certain rotation speed.
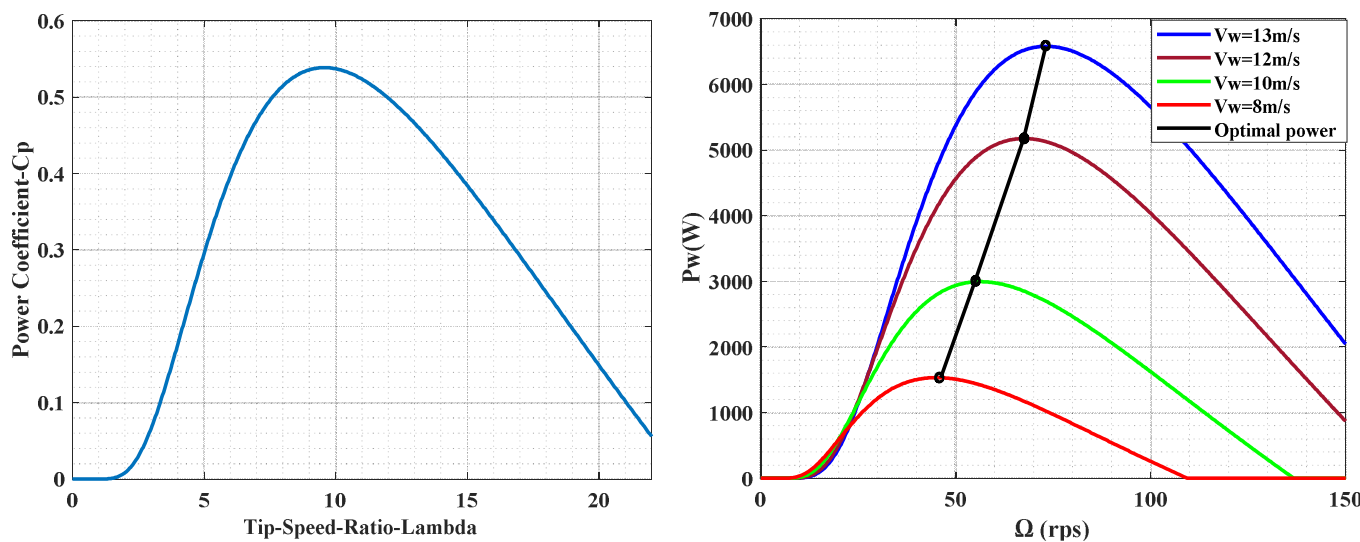

Fig. 2 Power and power coefficient characteristics at different wind level

\subsection{MODEL OF THE PERMANENT MAGNET MACHINE}

The following is a model of the permanent magnet machine in Park's coordinate system [15, $16,17]$ :

$$
\left\{\begin{array}{c}
\frac{d i_{d}}{d t}=-\frac{R_{S}}{L_{d}} i_{d}+\omega \frac{L_{q}}{L_{d}} i_{q}-\frac{V_{d}}{L_{d}} \\
\frac{d i_{q}}{d t}=-\omega \frac{L_{d}}{L_{q}} i_{d}-\frac{R_{S}}{L_{q}} i_{d}-\frac{V_{q}-\omega \cdot \varphi_{e}}{L_{q}}
\end{array}\right.
$$


The electromagnetic torque is given by:

$$
T_{e m}=\left(\frac{3}{2}\right)\left(\frac{P}{2}\right) \cdot \varphi_{m} \cdot i_{q}
$$

The parameters of PMSG are given in Table 1.

Table 1 PMSG parameters

\begin{tabular}{|c|c|c|c|c|}
\hline Rated Power & Rated Voltage & Frequency & $\begin{array}{c}\text { Number of } \\
\text { Poles }\end{array}$ & $\begin{array}{c}\text { Inertia Constant } \\
(\mathbf{M + T})\end{array}$ \\
\hline $5.5 \mathrm{Kw}$ & $200 \mathrm{~V}$ & $50 \mathrm{~Hz}$ & 12 & $7.856 \mathrm{Kg} . \mathrm{m}^{2}$ \\
\hline Stator Resistance & d-axis Reactance & q-axis Reactance & Field Flux & Nominal speed \\
\hline $0.3676 \Omega$ & $0.00355 \mathrm{H}$ & $0.00355 \mathrm{H}$ & $0.2867 \mathrm{~V} . \mathrm{s}$ & $70 \mathrm{rps}$ \\
\hline
\end{tabular}

\subsection{DC-DC BOOST CONVERTER}

The step-up converter is installed between the rectifier and the inverter for lad adaption. The dynamic model is expressed by the equations below $[18,19]$ :

$$
\left\{\begin{array}{l}
C_{\text {rect }} \frac{d V_{\text {rect }}}{d t}=i_{\text {rect }}-i_{L} \\
L \frac{d i_{L}}{d t}=-(1-D) \cdot V_{\text {bus }}+V_{\text {rect }} \\
C_{\text {bus }} \frac{d V_{\text {bus }}}{d t}=(1-D) \cdot i_{L}-\frac{V_{\text {bus }}}{R}
\end{array}\right.
$$

$D$ is the duty cycle $(0<D<1)$.

\subsection{IM MODEL}

The equation systems below offer the global model of the IM following Park transformation $[20,21]:$

$$
\left\{\begin{array}{c}
\frac{d i_{s d}}{d t}=-\left(\frac{1}{\sigma T_{s}}+\frac{1-\sigma}{\sigma} \cdot \frac{1}{T_{r}}\right) \cdot i_{s d}+\omega_{s} i_{s q}+\left(\frac{1-\sigma}{\sigma M} \cdot \frac{1}{T_{r}}\right) \cdot \varphi_{r d}+p \omega_{m} \cdot\left(\frac{1-\sigma}{\sigma M}\right) \cdot \varphi_{r q}-\left(\frac{1-\sigma}{\sigma M}\right) \cdot V_{r d}+\frac{1}{\sigma L_{s}} \cdot V_{s d} \\
\frac{d i_{s q}}{d t}=-\omega_{s} i_{s d}-\left(\frac{1}{\sigma T_{s}}+\frac{1-\sigma}{\sigma} \cdot \frac{1}{T_{r}}\right) \cdot i_{s q}-p \omega_{m} \cdot\left(\frac{1-\sigma}{\sigma M}\right) \cdot \varphi_{r d}+\left(\frac{1-\sigma}{\sigma M} \cdot \frac{1}{T_{r}}\right) \cdot \varphi_{r q}-\left(\frac{1-\sigma}{\sigma M}\right) \cdot V_{r q}+\frac{1}{\sigma L_{s}} \cdot V_{s q} \\
\frac{d \varphi_{r d}}{d t}=\frac{M}{T_{r}} \cdot i_{s d}-\frac{1}{T_{r}} \cdot \varphi_{r d}+\left(\omega_{s}-p \omega_{m}\right) \cdot \varphi_{r q}+V_{r d} \\
\frac{d \varphi_{r q}}{d t}=\frac{M}{T_{r}} \cdot i_{s q}-\frac{1}{T_{r}} \cdot \varphi_{r q}-\left(\omega_{s}-p \omega_{m}\right) \cdot \varphi_{r d}+V_{r q}
\end{array}\right.
$$

The electromechanical torque is calculated as follows:

$$
\frac{d \omega_{m}}{d t}=\frac{p}{J} \cdot \frac{M}{L_{r}} \cdot\left(\varphi_{r d} \cdot i_{s q}-\varphi_{r q} \cdot i_{s d}\right)-\frac{f}{J} \omega_{m}-\frac{p}{J} C_{r e s}
$$

The mechanical equation is:

$$
T_{e}=P \cdot \frac{M}{L_{r}} \cdot\left(\varphi_{r d} \cdot i_{s q}-\varphi_{r q} \cdot i_{s d}\right)
$$


The rotor is short-circuited for the IM type; so $V_{r d}=V_{r q}=0$.

\subsection{MODEL OF THE INVERTER}

A voltage inverter controls the connection of an IM to the pump system. A boost chopper provides power to this inverter. The DC-AC converter's three-phase output voltages are provided by [22, 23, 24]:

$$
\left[\begin{array}{l}
V_{a} \\
V_{b} \\
V_{c}
\end{array}\right]=\frac{V_{b u s}}{3} \cdot\left[\begin{array}{ccc}
2 & -1 & -1 \\
-1 & 2 & -1 \\
-1 & -1 & 2
\end{array}\right] \cdot\left[\begin{array}{c}
S_{1} \\
S_{2} \\
S_{3}
\end{array}\right]
$$

$S_{1}, S_{3}$ and $S_{5}$ are the switching functions of the inverter transistors.

\subsection{IM CONTROL}

To minimize computation time and make the synthesis of speed and current regulators easier, the vector control of the IM provided by a voltage inverter at the stator level is discussed in this section.

The proposed technique overcomes these problems to achieve a condition similar to that of a direct current motor (DCM). Field coordinates have been introduced, allowing the stator current vector to become split into two parts. For a squirrel cage machine, one generates torque and the other flux. Because of the benefits of computer-implemented vector control, IMs can now be used in high-performance drives. To obtain the stator current vector for the squirrel cage induction motor (SCIM), two kinds of control are employed [25, 26, 3]:

- The first method proposed by Blaschke,

- The second method proposed by Hasse.

Flow-oriented control is a term that has recently appeared in the literature related to electric motor control approaches. The idea is well-known in the context of DC motors. In the case of AC machines, however, this is not the case. As a result, reciprocating machine oriented flow control is an orientation control of these two quantities [27, 28]. In this paper, voltage control is proposed using the stator flux oriented coordinate system $(d-q)$.

\subsubsection{ROTOR FLUX ORIENTATION}

\subsubsection{SPEED ADJUSTMENT BY VECTOR CONTROL}

It is possible to obtain an expression of the torque in which two orthogonal currents $\left(\Phi_{r d}, i_{s q}\right)$ are included if the frame of reference $(d-q)$ is selected properly so that the rotor flux is aligned with the axis $(d)$ (Figure 3). A flux generator and a torque generator are the two types of generators. $\Phi_{r d}=\Phi_{r}$, et $\Phi_{r q}=0$. 


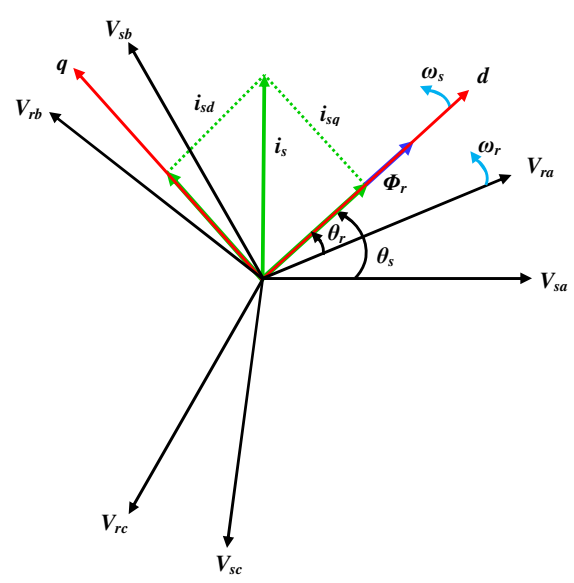

Fig. 3 Vectorial control Principle

The expression of the electromagnetic couple is as follows $[29,25,26]$ :

$$
T_{e}=p \cdot \frac{M}{L_{r}} \cdot \varphi_{r d} \cdot i_{s q}
$$

\subsubsection{ESTIMATION OF ROTOR FLUX AND SPEED}

$\Phi_{r q}$ is zero, from Eq. (6), the position of the stator flow vector is calculated as follows:

$$
\begin{gathered}
\omega_{s}-\omega_{m}=S \omega_{s}=\frac{1}{T_{r}} \cdot\left(\frac{M}{\varphi_{r d}}\right) \cdot i_{s q} \\
\varphi_{r_{-} e s t}=\frac{M}{T_{r} s+1} i_{s d}
\end{gathered}
$$

This simplifies the whole system of Eqs. (6) by setting $\Phi_{r q}=0$. A new model for the SCIM is obtained, which can be put in a state form with vector in the following state $\left(i_{s d}, i_{s q}, \phi_{r d}, \omega_{m}\right)$ :

$$
\left\{\begin{array}{c}
\frac{d i_{s d}}{d t}=-\left(\frac{1}{\sigma T_{s}}+\frac{1-\sigma}{\sigma} \cdot \frac{1}{T_{r}}\right) \cdot i_{s d}+\omega_{s} i_{s q}+\left(\frac{1-\sigma}{\sigma M} \cdot \frac{1}{T_{r}}\right) \cdot \varphi_{r d}+\frac{1}{\sigma L_{s}} \cdot V_{s d} \\
\frac{d i_{s q}}{d t}=-\omega_{s} i_{s d}-\left(\frac{1}{\sigma T_{s}}+\frac{1-\sigma}{\sigma} \cdot \frac{1}{T_{r}}\right) \cdot i_{s q}-p \omega_{m} \cdot\left(\frac{1-\sigma}{\sigma M}\right) \cdot \varphi_{r d}+\frac{1}{\sigma L_{s}} \cdot V_{s q} \\
\frac{d \varphi_{r d}}{d t}=\frac{M}{T_{r}} \cdot i_{s d}-\frac{1}{T_{r}} \cdot \varphi_{r d}
\end{array}\right.
$$

Two new control variables $V_{s_{-} r e g}$ and $V_{s q-r e g}$ are defined and reconstitute the voltages $V_{s d}$ and $V_{s q}$ from $V_{s d \_r e g}$ and $V_{s q \_ \text {reg }}$ voltages.

$$
\left\{\begin{array}{l}
V_{s d_{-} r e g}=\sigma L_{s} \frac{d i_{s d}}{d t}+\sigma L_{s}\left(\frac{1}{\sigma T_{s}}+\frac{1-\sigma}{\sigma} \cdot \frac{1}{T_{r}}\right) i_{s d} \\
V_{s q_{-} r e g}=\sigma L_{s} \frac{d i_{s q}}{d t}+\sigma L_{s}\left(\frac{1}{\sigma T_{s}}+\frac{1-\sigma}{\sigma} \cdot \frac{1}{T_{r}}\right) i_{s q}
\end{array}\right.
$$




\subsubsection{ADJUSTMENT OF THE INTERNAL LOOP OF THE CURRENT IDQS}

Speed regulation schemes consist of two stages: the first consists of the current regulation loops and the second is for speed regulation. This is justified since the dynamics of speed is very slow compared to that of currents. As a result, while the currents are being controlled, the speed is always considered to remain constant (in conventional regulations). The reference current's expression $i_{s q \_r e f}$ is given by:

$$
i_{s q_{-} r e f}=\frac{T_{e_{-} r e f}}{\varphi_{r_{-} r e f}}
$$

At constant speed:

$$
\frac{i_{d q s}}{V_{d q s_{-} r e g}}=\frac{1}{\left(\sigma L_{s} s+\sigma L_{S}\left(\frac{1}{\sigma T_{s}}+\frac{1-\sigma}{\sigma} \cdot \frac{1}{T_{r}}\right)\right)}
$$

The current regulation loop $i_{s q}$ can be represented by the block diagram of the Figure 4:

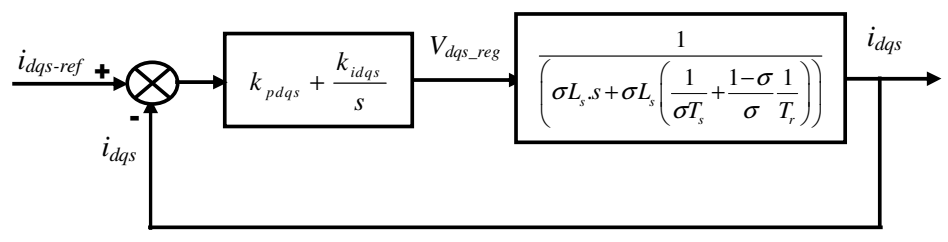

Fig. 4 Current regulation block diagram (idqs

The closed loop transfer function and the characteristic polynomial are as follow:

$$
\begin{gathered}
\frac{i_{d q s}(s)}{i_{d q s_{-} r e f}}=\frac{\left(k_{p d q s} \cdot s+k_{i d q s}\right) \cdot \frac{1}{\sigma L_{s}}}{s^{2}+\left(\frac{k_{p d q s}}{\sigma L_{s}}+\frac{1}{\sigma T_{s}}+\frac{(1-\sigma)}{\sigma T_{r}}\right) \cdot s+\frac{k_{i d q s}}{\sigma L_{s}}} \\
P(s)=s^{2}+\left(\frac{k_{p d q s}}{\sigma L_{s}}+\frac{1}{\sigma T_{s}}+\frac{(1-\sigma)}{\sigma T_{r}}\right) \cdot s+\frac{k_{i d q s}}{\sigma L_{s}}
\end{gathered}
$$

By imposing on the characteristic closed-loop polynomial, two following complex conjugate poles: $s_{1,2}=\rho \cdot(-1 \pm j), \rho>0$,

where:

$$
P(s)=s^{2}+2 \rho \cdot s+2 \rho^{2}=0
$$

The term-by-term identification of the two Eqs. (18) and (19) leads us to write:

$$
\left\{\begin{array}{c}
k_{p d q s}=2 \sigma \cdot L_{s} \cdot \rho-\left(\frac{1}{T_{s}}+\frac{(1-\sigma)}{T_{r}}\right) \cdot L_{s} \\
k_{i d q s}=2 \sigma \cdot L_{s} \cdot \rho^{2}
\end{array}\right.
$$




\subsubsection{ADJUSTMENT OF THE INTERNAL ROTOR FLUX LOOP $\Phi_{R}$}

To maintain the appropriate flux, the estimated rotor flux regulator allows the determination of the direct reference current. The internal loop must be extremely fast in comparison to the flux for the cascade to be justifiable.

The flux equation is as follows:

$$
\frac{\varphi_{r_{-} e s t}}{i_{s d}}=\frac{M}{T_{r} s+1}
$$

By associating this function with a PI regulator, the flux regulation functional diagram is presented as follows:

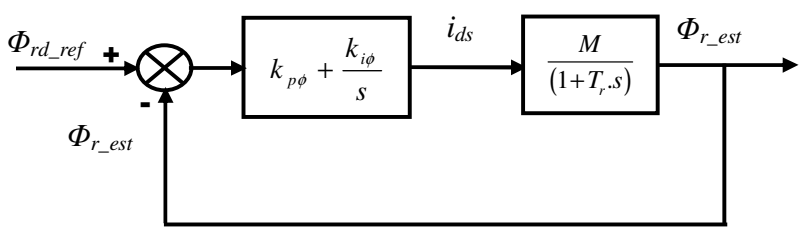

Fig. 5 Flux regulation functional diagram

The closed loop transfer function which is calculated from the previous diagram can be given by:

$$
\begin{gathered}
\frac{\varphi_{r_{-} e s t}(s)}{\varphi_{r_{-} r e f}(s)}=\frac{\left(k_{p \varphi} \cdot s+k_{i \varphi}\right)\left(\frac{M}{T_{r}}\right)}{s^{2}+\left(\frac{1}{T_{r}}+\frac{k_{p \varphi} \cdot M}{T_{r}}\right) \cdot s+k_{i \varphi}\left(\frac{M}{T_{r}}\right)} \\
s^{2}+\left(\frac{1}{T_{r}}+\frac{k_{p \varphi} \cdot M}{T_{r}}\right) \cdot s+k_{i \varphi}\left(\frac{M}{T_{r}}\right)=0
\end{gathered}
$$

The determination of the two coefficients $k_{p \phi}$ and $k_{i \phi}$ is the same as for the determination of the current $i_{d q s}$.

\subsubsection{ADJUSTMENT OF THE EXTERNAL SPEED LOOP}

The speed regulator is used to determine the reference torque to maintain the corresponding speed. The mechanical equation is:

$$
\frac{\omega_{m}(s)}{T_{e}(s)}=\frac{p}{J s+f}
$$

The speed control functional diagram based on the PI regulator is presented as follows:

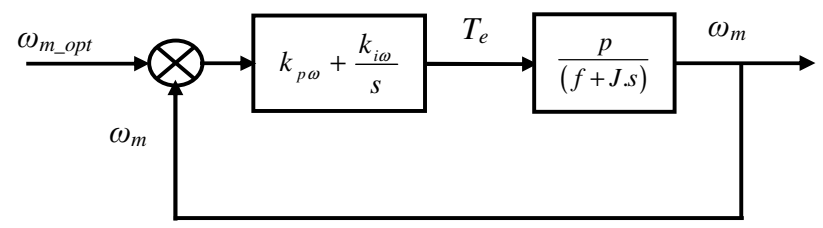

Fig. 6 Functional diagram of speed control

Based on the speed control functional diagram, the closed loop transfer function is as follows: 


$$
\begin{gathered}
\frac{\omega_{m}(s)}{\omega_{m_{-} o p t}(s)}=\frac{\left(k_{p \omega} \cdot s+k_{i \omega}\right)\left(\frac{p}{J}\right)}{s^{2}+\left(\frac{f+k_{p \omega} \cdot p}{J}\right) \cdot s+k_{i \omega}\left(\frac{p}{J}\right)} \\
P(s)=s^{2}+\left(\frac{f+k_{p \omega} \cdot p}{J}\right) \cdot s+k_{i \omega}\left(\frac{p}{J}\right)=0
\end{gathered}
$$

By imposing two complex conjugate poles $s_{1,2}=\rho \cdot(-1 \pm j), \rho>0$, the following is obtained:

$$
\left\{\begin{array}{c}
k_{i \omega}=\frac{2 J \cdot \rho^{2}}{p} \\
k_{p \omega}=\frac{2 J \cdot \rho-f}{p}
\end{array}\right.
$$

Generally, the rotor flux is kept constant $\left(\Phi_{r_{-} r e f}\right)$ for rotor speeds less than or equal to the nominal speed of the machine $\left(\omega_{m}{ }^{n}\right)$. The reference value of the quadrature component of the stator current $i_{s q_{-} \text {ref }}$ is given according to:

$$
i_{s q_{-} r e f}=\frac{T_{e_{-} r e f}}{\varphi_{r_{-} r e f}}
$$

Taking into account that the IM is supplied by a voltage inverter with $\Phi_{r q}=0$, the stator voltage equation is obtained by:

$$
\left\{\begin{array}{l}
V_{d_{-} r e f}=V_{d_{-} r e g}-V_{c d} \\
V_{q_{-} r e f}=V_{q_{-} r e g}-V_{c q}
\end{array}\right.
$$

The traditional compensation approach [29] typically eliminates the connection between the two axes. The coupling terms are set up so that the remaining voltages and current components have a first-order connection. So:

$$
\left\{\begin{array}{c}
V_{c d}=\omega_{s} i_{s q}+\left(\frac{1-\sigma}{\sigma M} \cdot \frac{1}{T_{r}}\right) \varphi_{r d} \\
V_{c q}=-\omega_{s} i_{s d}-p \omega_{m}\left(\frac{1-\sigma}{\sigma M}\right) \varphi_{r d}
\end{array}\right.
$$

The control structure consists of a SCIM connected to a water pump. The SCIM is powered by a boost chopper and a voltage inverter based on a diode bridge. The inverters' output voltages are regulated by a pulse width modulation (PWM) method, which allows simultaneous changes in output voltage and frequency. This includes comparing and calculating three voltages $\left(V_{a_{-} \text {ref }}, V_{b_{-} \text {ref }}, V_{c_{-} \text {ref }}\right)$ using the inverse of the PARK transformation $\left(V_{d_{-} \text {ref }}, V_{q_{-} \text {ref }}\right)$.

Based on the turbine characteristics, the method that maximizes point power enabled determining the machine's ideal reference speed. The reference speed is determined by the wind generator's maximum power, which drives the SCIM-pump system. The following equation is used for the ideal speed:

$$
\omega_{o p t}=\sqrt[3]{\frac{I_{o p t} \cdot V_{o p t}}{k_{p} \cdot \eta_{p} \cdot \eta_{m} \cdot \eta_{c} \cdot \eta_{h}}}
$$




\subsection{PUMP MODELLING}

The main characteristics for torque and load power $T_{L}(\mathrm{PL})$ are proportional to the square of the rotor speed. These characteristics are depicted by the following equations $[30,29,11,3]$ :

$$
\begin{gathered}
T_{L}=k \omega_{m}^{2} \\
P_{L}=T_{L} \cdot \omega_{m}=k \omega_{m}^{3}
\end{gathered}
$$

with $k>0$.

\section{MPPT CONTROL}

It is important to specify the control rules in order to assure operation at maximum power and under ideal circumstances. The WECS chain optimization is required to achieve the MPPT algorithm. Furthermore, utilizing a simpler and less expensive converter chain, indirect control of wind power systems is feasible. It is constructed around a three-phase diode bridge and a standard step-up converter.

\subsection{P\&O TECHNIQUE}

The perturbation and observation $(P \& O)$ technique is widely used in industrial applications. As the algorithm is easy to implement, the objective is to interrupt the system by increasing or decreasing the module's operating speed and to observe its influence on the line's output power $[3,31,32]$.

\subsection{MPPT USING FLC TECHNIQUE}

The MPPT approach based on the idea of fuzzy sets is used. The FLC, as the conventional regulator, has its position in the regulatory system due to linguistic rules, etc. In order to approach the optimal point, the observed behavioral rules must be relatively simple for the studied system to be established [33, 11]. The regulations in the studied system (WECS connected to a water pump) are based on variations in wind power $\left(\Delta P_{w}\right)$ and the rotation speed $(\Delta \Omega)$ of the wind turbine.

Table 2 and Eq. (33) show the inputs and the outputs of the FLC which are $\Delta P_{w}, \Delta \Omega$ and $\Delta \Omega_{-} r e$. The FLC structure is shown in Figure 7.

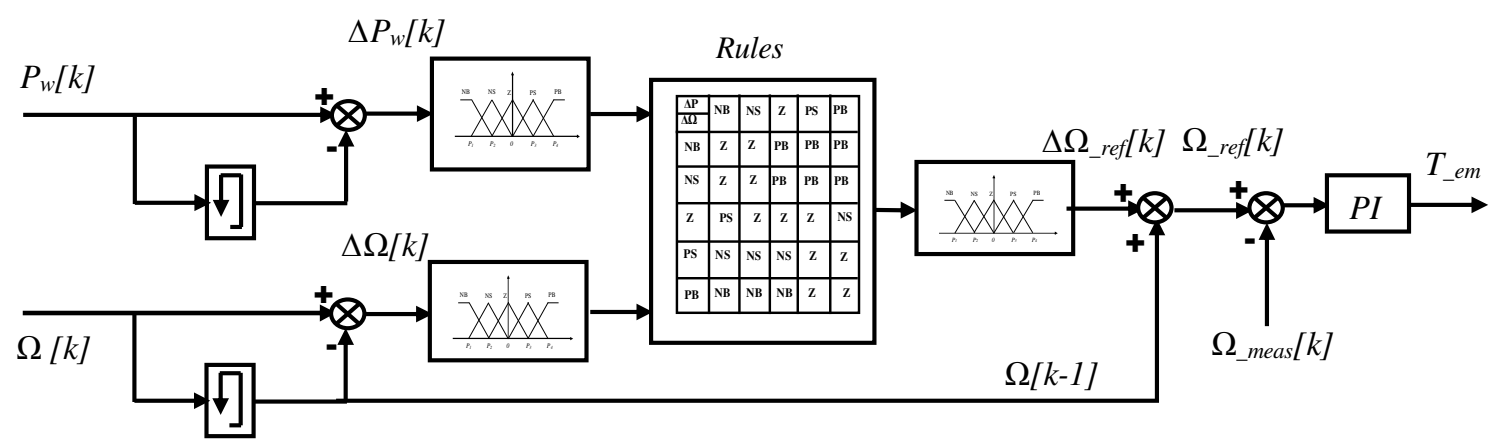

Fig. 7 Structure of the fuzzy MPPT controller applied to the WECS 
The fuzzy MPPT controller is based on measuring the wind power $\left(\Delta P_{w}\right)$ variation of and the rotational speed $(\Delta \Omega)$ of the wind turbine which offers a variation $\left(\Delta \Omega_{-} r e f\right)$ of the rotational speed setpoint ( $\Omega_{-}$ref) according to Eq. (33).

$$
\left\{\begin{array}{c}
\Delta P_{w}=P_{w}(k)-P_{w}(k-1) \\
\Delta \Omega=\Omega(k)-\Omega(k-1) \\
\Omega(k)_{r e f}=\Omega(k-1)+\Delta \Omega(k)_{r e f}
\end{array}\right.
$$

The speed of the wind turbine is controlled according to the speed reference $\left(\Omega_{-}\right.$ref $)$obtained at the fuzzy controller's output. Furthermore, the speed controller's output determines the reference of the electromagnetic torque of the tested machine.

The fuzzy controller contains three blocks as follows: fuzzification, inference, and defuzzification [1, 11,34]. The fuzzy input variables and membership functions must be defined in advance. The fuzzy sets for input variables are respectively: power $\left(\Delta P_{w}\right)$ variation and voltage variation $(\Delta \Omega)$. Figure 8 presents the triangular functions for the input variables. The linguistic variables can be defined as follow:

Negative Big (NB), Negative Small (NS), Zero (Z), Positive Small (PS), and Positive Big (PB). The quality of the input and output FMs can be expressed as follows [35]:

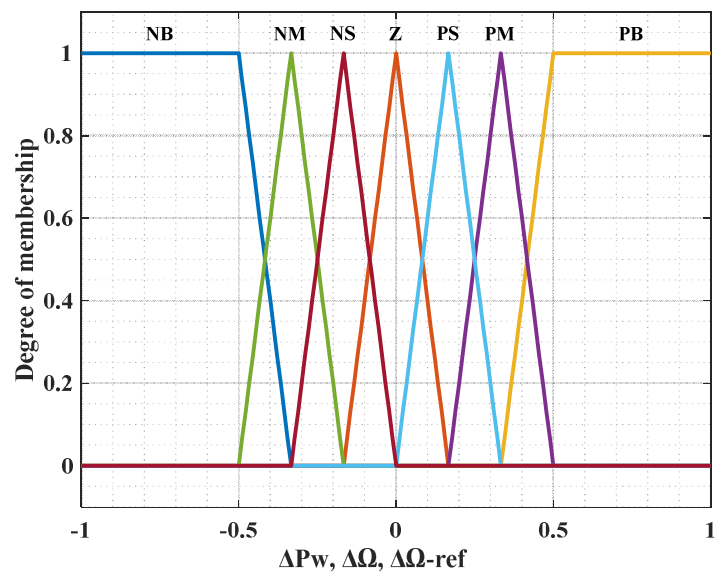

Fig. 8 Membership functions of $\Delta P_{w}, \Delta \Omega$, and $\Delta \Omega_{\text {ref }}$

As defuzzification is the last step in the regulation system, it converts the linguistic value of $\left(\Delta \Omega_{\text {-ref }}\right)$ into a digital value. Mamdani $[1,11,35]$ is used to define fuzzy inference as the defuzzification method is the center of gravity.

$$
\Delta \Omega_{-} r e f=\frac{\sum_{i=1}^{M} \mu\left(\Delta \Omega_{i}\right) \cdot \Delta \Omega_{i}}{\sum_{i=1}^{M} \mu\left(\Delta \Omega_{i}\right)}
$$

\subsection{OPTIMIZATION ALGORITHM}

In general, optimization techniques are used to address a variety of issues, including finding zeros functions, minimizing the distance between the curve and the measured points, intersections of functions, and solving multi-variable equation systems. 


\subsubsection{THE PSO ALGORITHM}

The PSO algorithm was introduced by Kennedy, Eberhart, and Shi [36]. It is a metaheuristic optimization technique that uses a large number of particles scattered in search around very large spaces of candidate solutions. The method is based on both the position and the velocity of each particle since each has a random speed. Mathematically, the PSO algorithm uses a swarm made up of $n_{p} \in \mathbb{N}$ particles, that is $\left(X_{i}\right)_{i=1,2, \ldots . n_{p}}$.

In search of the suboptimal $X^{*}$ solution that minimizes the objective function called $J$. The velocity position of the particle vectors $i^{\text {th }}$ are given respectively by $X_{i}=\left(X_{i, 1}, X_{i, 2 \ldots \ldots . . .} X_{i, q}\right)$ and $V_{i}$ $=\left(V_{i 1}, V_{i, 2} \ldots \ldots . . V_{i, q}\right)$. They are determined by the following iterative expressions $[37,38,39,40$, 36]:

$$
\left\{\begin{array}{c}
V_{i}^{l+1}=c_{0} \cdot V_{i}^{l}+c_{1} \cdot r_{1, i}^{l}\left(X_{i}^{\text {best }, l}-X_{i}^{l}\right)+c_{2} \cdot r_{2, i}^{l}\left(X_{\text {swarm }}^{\text {best } l}-X_{i}^{l}\right) \\
X_{i}^{l+1}=X_{i}^{l}+V_{i, j}^{l+1}
\end{array}\right.
$$

Where $l=1,2, \ldots . . l_{\max }$ is the number of iterations previously provided by the user $[8,9] . c_{0}, c_{1}$ and $c_{2}$ are respectively the inertia factor, the cognitive (individual) and social (group) learning relationships. $r_{1, i}^{l}$ and $r_{2, i}^{l}$ are random numbers evenly distributed over the interval $[0,1]$. $X_{i}^{\text {best }, l}$ and $X_{\text {swarm }}^{\text {best }, l}$ are respectively the best position previously obtained by the particle and the best position obtained by the whole swarm at the current iteration $l$ which are given by $[11,12]$ :

$$
\left\{\begin{array}{c}
X_{i}^{\text {best }, l}=\min \left\{J\left(X_{i}^{j}\right), 0 \leq j \leq l\right\} \\
X_{\text {swarm }}^{\text {best }, l}=\min \left\{J\left(X_{i}^{l}\right), \forall i\right\}
\end{array}\right.
$$

To simplify, the stop condition imposed in step 2 is replaced by the maximum of the iteration numbers $l_{\max }$ previously chosen by the user.

\subsubsection{STRATEGY OF THE GENETIC ALGORITHM (GA)}

The GA consists of the following steps [41, 42]:

Step 1: Randomly generate $\mathrm{N}$ chromosomes in the initial population in the search space with the chromosome $=\left[X_{1}, X_{2}, \ldots, X_{n}\right]$, where $X_{\min } \leq X_{1,2, \ldots ., n} \leq X_{\max }$;

Step 2: Calculate the objective function for each chromosome.

Step 3: Apply the following operators:

a) Perform reproduction, i.e., pick the best probability chromosomes based on their objective function values.

b) Cross over the chromosomes selected in the above step using the crossing probabilities.

c) Perform a mutation on the chromosomes generated in the above step by the probability of mutation.

Step 4: The process can be stopped if the stopping condition is reached or even the optimum solution is obtained. Alternatively, repeat steps 2 to 4 until the stop condition is met.

Step 5: The optimal solution $X^{*}$, corresponding to the best objective function, $X^{*}=\min _{X_{i}^{j}}\left(J\left(X_{i}^{j}\right), \forall i, j\right)$ is thus obtained. 


\subsection{FUZZY LOGIC OPTIMIZATION STRATEGY USING GENETIC ALGORITHM AND PSO}

21 fuzzy parameters may be determined based on the resolution of the optimization problem. The objective function also displays the total of the Mean Square Error (MSE) values. Under wind, the turbine value equals $12.3 \mathrm{~m} / \mathrm{s}$. The error, which is the difference at each sampling time $k$, can be found between the optimum powers supplied. Therefore, the formula is obtained as follows:

$$
J_{k}(k)=P_{o p t}(k)-P_{\text {sim }}(k)
$$

The tuning process of PSO/GA of the Fuzzy MPPT controller applied to the wind system is shown in Figure 9.

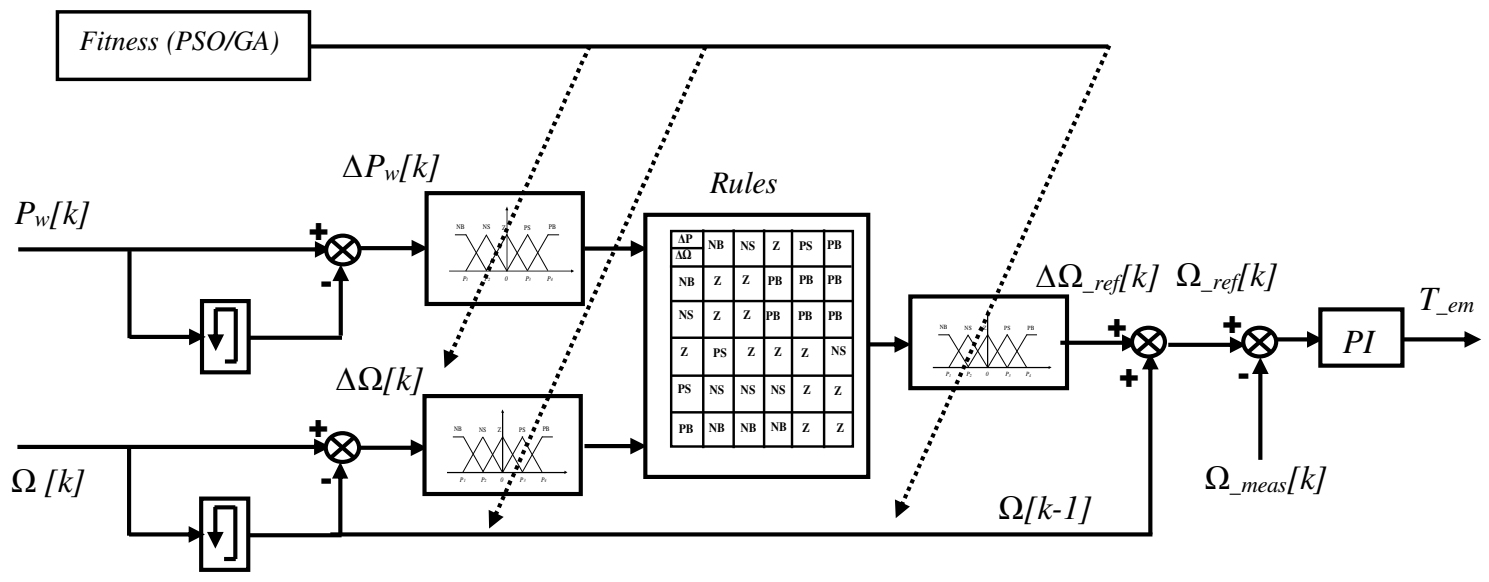

Fig. 9 Schema of tuning process by PSO/GA of Fuzzy MPPT controller applied to the wind system

Figure 10 (a) shows the seven membership function parameters following the GA, whereas Figure 10 (b) shows the PSO tuning process.

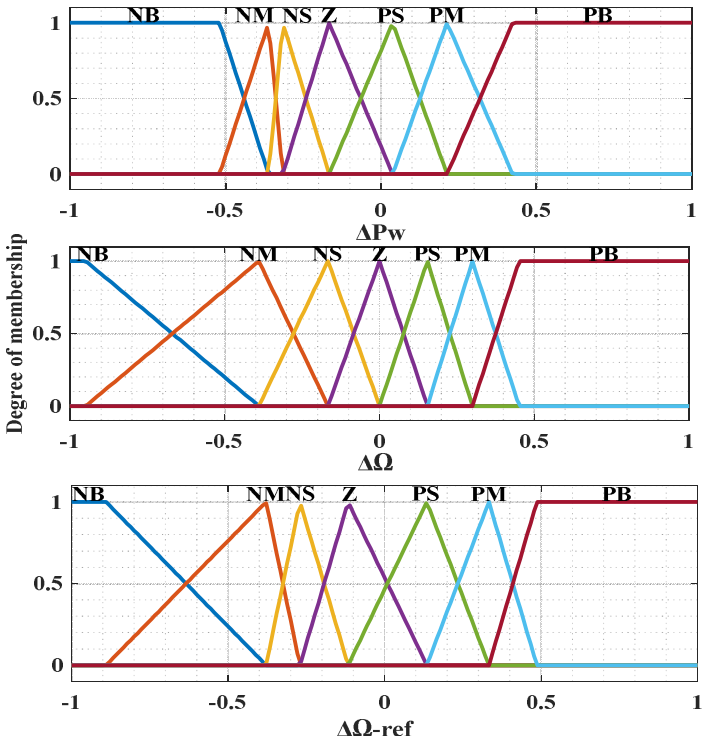

(a)
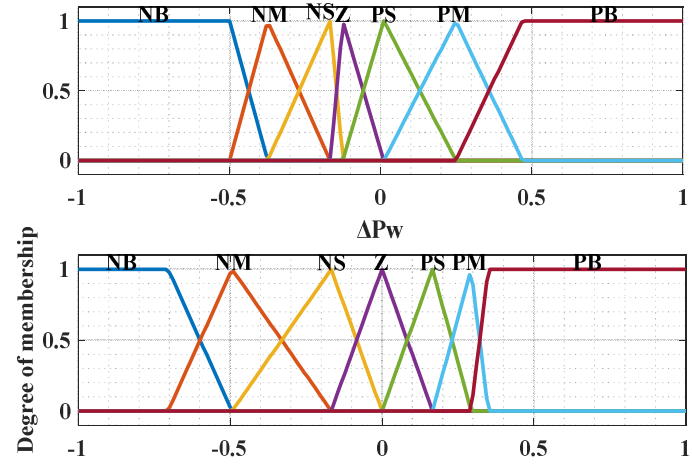

$\Delta \Omega$

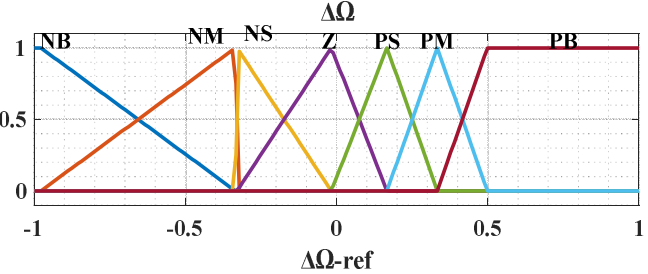

(b)

Fig. 10 Membership functions optimized by GA (a) and PSO (b) 
The objective function value (fitness function) during the search for the optimal solution is presented in Figure 11. When there is no reduction in total control error, the iteration number equals 70 , as shown in Figure 11. At the level of convergence of the value of zero, it's crucial to observe the difference between Figure 11 (a) and Figure 11 (b), the first based on the GA and the second on the PSO algorithm.

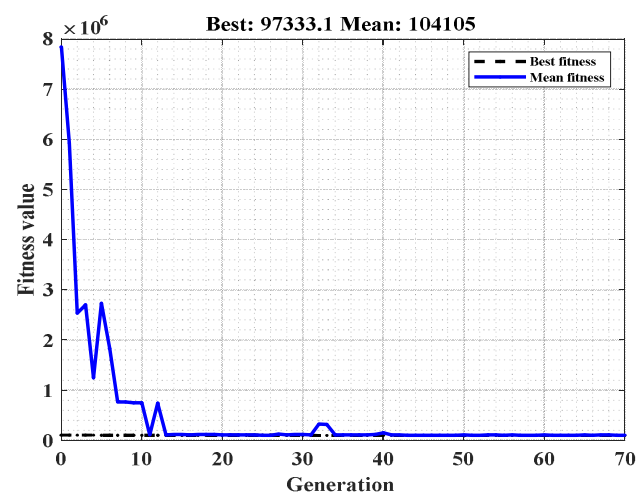

(a)

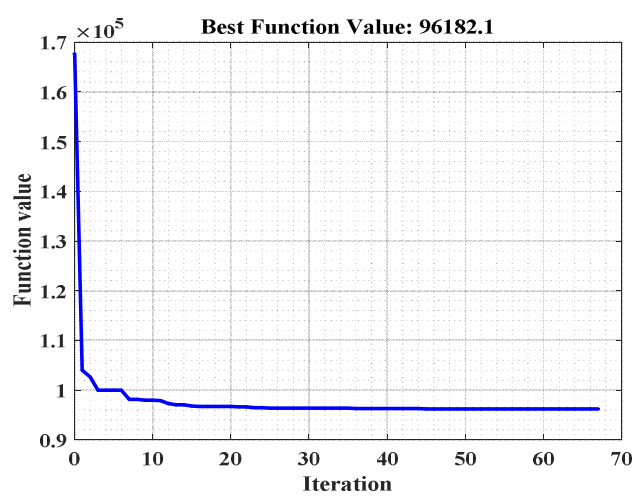

(b)

Fig. 11 Objective function of (a): GA and (b): PSO

The MF parameters before and after the tuning process (PSO and GA) are presented in Table 2.

Table 2 Membership function Parameters before and after the PSO/GA

\begin{tabular}{|cccc|}
\hline MF & Before PSO/GA & After PSO & After $\boldsymbol{G A}$ \\
\hline Input $(\Delta P)$ & -1 & -0.50 & -0.518 \\
& -0.67 & -0.373 & -0.361 \\
-0.34 & -0.166 & -0.315 \\
& 0 & -0.125 & -0.166 \\
Input $(\Delta \Omega)$ & 0.34 & 0.010 & 0.0373 \\
& 0.67 & 0.248 & 0.212 \\
\hline 1 & 0.468 & 0.423 \\
& -1 & -0.704 & -0.948 \\
& 0.67 & -0.493 & -0.389 \\
& -0.34 & -0.166 & -0.166 \\
0 & 0 & -0.0001 \\
& 0.34 & 0.166 & 0.154 \\
& 0.67 & 0.293 & 0.300 \\
\hline 1 & 0.349 & 0.450 \\
& -1 & -0.978 & -0.889 \\
& -0.67 & -0.334 & -0.378 \\
& -0.34 & -0.329 & -0.270 \\
0.34 & -0.0173 & -0.116 \\
& 0.67 & 0.166 & 0.135 \\
& 1 & 0.333 & 0.333 \\
& & 0.498 & 0.486 \\
\hline$\left.\Omega_{r e f}\right)$ & &
\end{tabular}




\section{SIMULATION, DISCUSSION AND RESULTS}

Variable level winds were applied to the system, distributed over three-time intervals.

According to the results shown in Figures 12 and 13, the MPPT controller, using various methods, leads the generator wind to achieve its maximum power point independent of weather conditions. This efficiency may be seen at the level of the wind generator voltage and power, which are well-regulated and follow their references after a response time of around $0.01 s$.

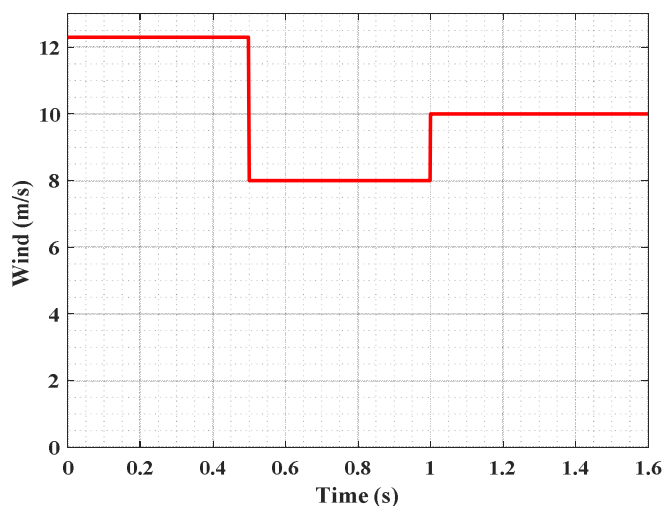

Fig. 12 Variation in wind speed

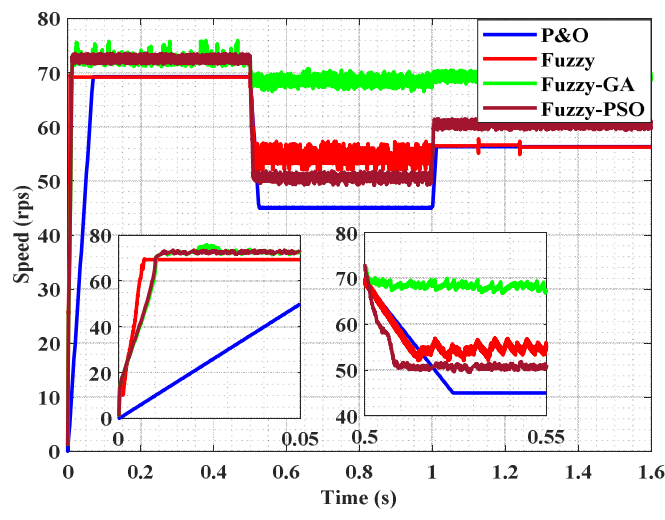

Fig. 13 Optimal speed of the turbine

The quantity fluctuations are acceptable, owing to the fact that the system oscillates around the wind generator's maximum power point. It's apparent that the oscillations emerge more frequently when the wind speed is low.

Figures 14, 15 and 16 represent the different curves obtained by controlling the maximum power of the wind generator transmitted to the PMSG (Figure 14). This generator transmits the power to a booster chopper through a unidirectional rectifier. It serves as a connector between the wind turbine and the assembly (inverter with pump system). Figures 18, 19, 20 and 21 demonstrate the IM's oriented rotor flux control principle.

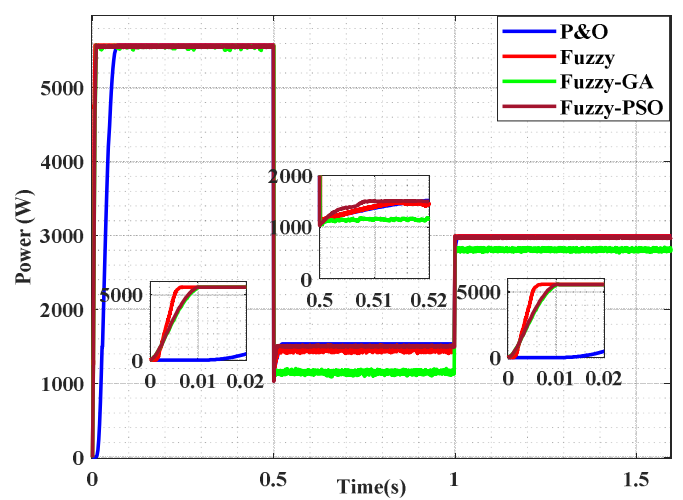

Fig. 14 Optimal mechanic power of the turbine

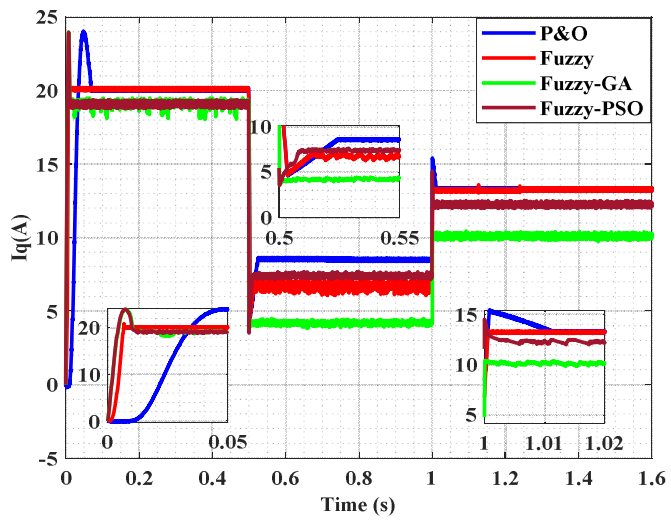

Fig. 15 Control current of the DC-DC converter 


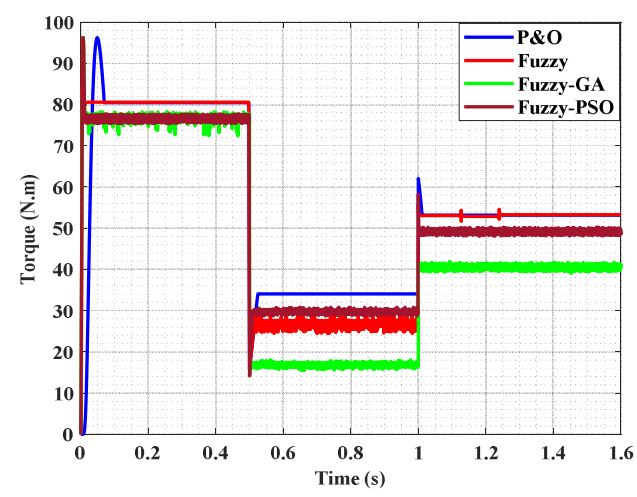

Fig. 16 Optimal torque of the turbine

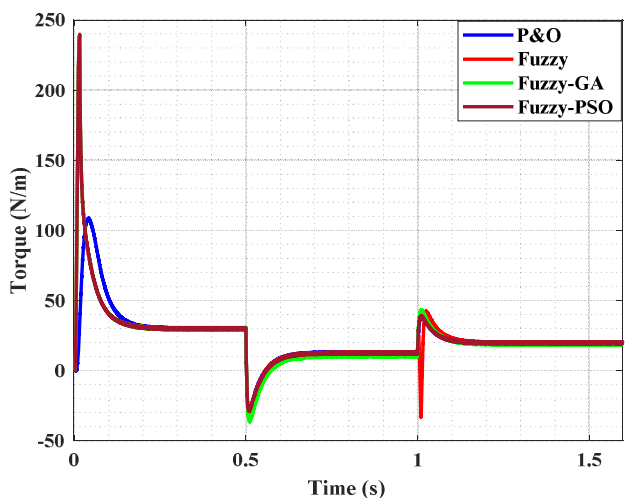

Fig. 18 Optimal torque of the IM

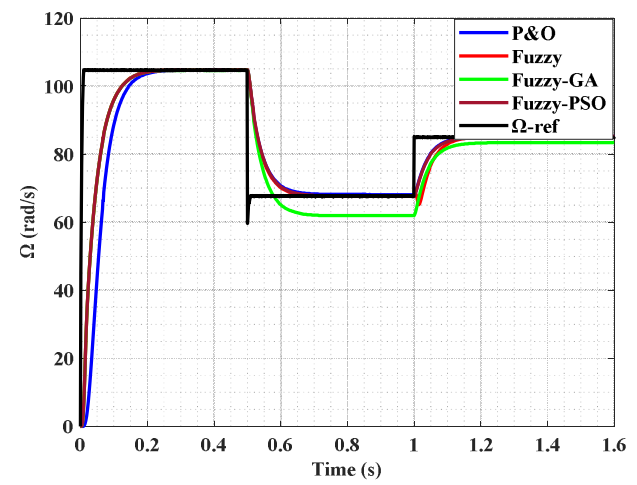

Fig. 20 Regulation of the IM speed

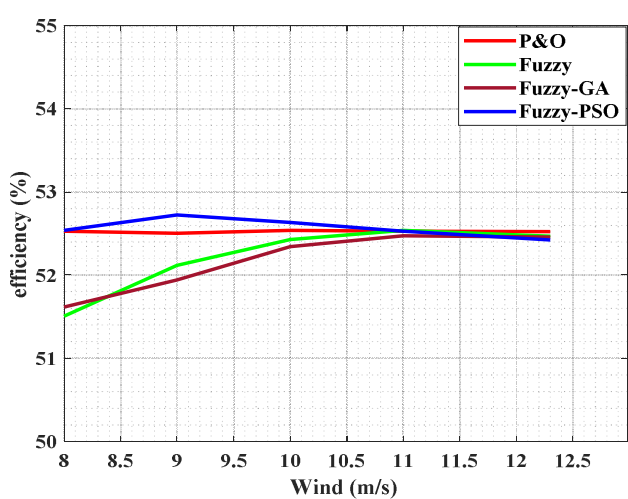

Fig. 22 Efficiency of the motor pump

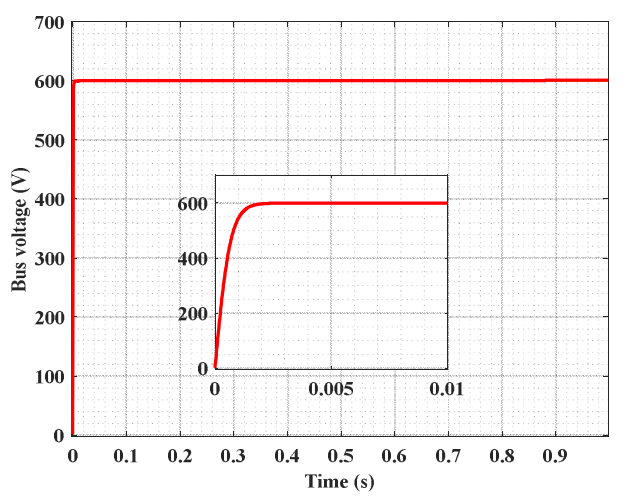

Fig. 17 DC link voltages (bus voltage)

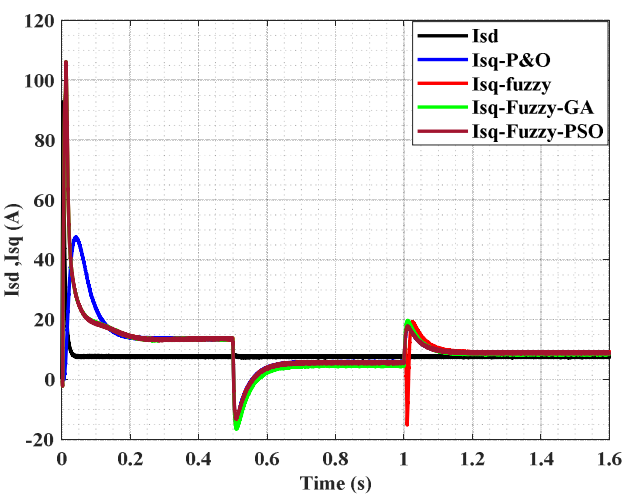

Fig. 19 Regulation of the IM currents

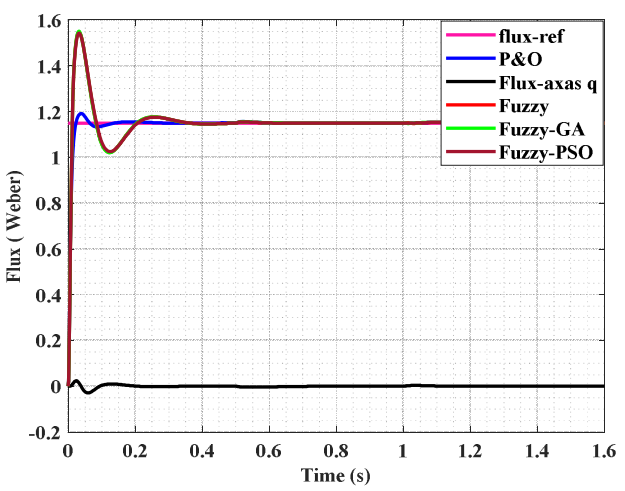

Fig. 21 Adjustment of the rotor flow

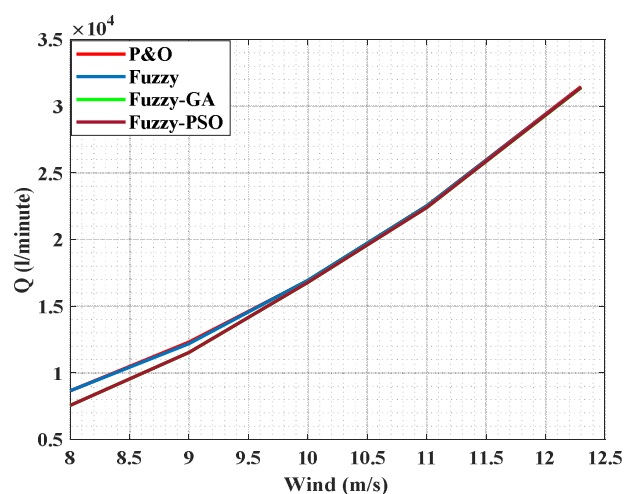

Fig. 23 Evolution of water as a function of wind 
The results demonstrate that the system is well optimized regardless of the change in wind speed. Using various optimization approaches (MPPT), the system's operating (Figure 14) is improved by wind speeds ranging from 8 to $12.3 \mathrm{~m} / \mathrm{s}$. Compared to the other approaches mentioned above, the fuzzy logic-PSO methodology has shown good results. The overall efficiency of the whole system (generator and motor pump) is low. It has a $50 \%$ similarity to a wind turbine.

\section{CONCLUSION}

In this work, we propose the WECS in combination with water pumping, which is a cost-free alternative to using the electrical grid. After a comparative analysis, we came to a final judgment about the best performance of the system.

The results demonstrate that the wind system can operate steadily and keep pace with the maximum power point in different meteorological conditions, such as wind speed changes.

This research provided a quicker FLC tuning procedure by altering the membership function mapping to reach the desired set point. The proposed optimum fuzzy logic MPPT inverter controller has shown promising results for WECS in a long-term grid application. Compared to other approaches, the fuzzy logic-PSO methodology has shown good results. The results demonstrate that the system is well optimized throughout a wide range of wind speeds.

\section{ACKNOWLEDGMENT}

This project was financially supported by the Directorate General for Scientific Research and Technological Development - Algerian Ministry of Higher Education and Scientific Research.

\section{REFERENCES}

[1] A. Borni, T. Abdelkrim, L. Zaghba, A. Bouchakour, A. Lakhdari, L. Zaarour, Fuzzy logic, PSO based fuzzy logic algorithm and current controls comparative for grid-connected hybrid system, AIP Conference Proceedings, Vol. 1814, No. 1, 020006, 2017.

\section{https://doi.org/10.1063/1.4976225}

[2] S. Bouketta, Y. Bouchahm, Numerical evaluation of urban geometry's control of wind movements in outdoor spaces during winter period, Case of Mediterranean climate, Renewable Energy, Vol. 146, pp. 1062-1069, 2020.

https://doi.org/10.1016/j.renene.2019.07.012

[3] A. Bouchakour, M. Brahami, A. Borni, Comparative Study on Photovoltaic Pumping Systems Driven by Different Motors Optimized with Sliding Mode Control, International Journal of Engineering and Technology Innovation, Vol. 7, No. 3, pp. 201-216, 2017.

[4] G. Esmaili, M.S.E.E. Application of advanced power electronics in renewable energy sources and hybrid generating systems, Doctorat Thesis, Graduate School of the Ohio State University, 2006.

[5] P. Sai Manoj, A. Vijayakumari, K. Kottayil Sasi, Development of a comprehensive MPPT for grid-connected wind turbine driven PMSG, Wind Energy, Vol. 22, No. 6, pp. 732-744, 2019. https://doi.org/10.1002/we.2318 
A. Borni, M. Bechouat, N. Bessous, A. Bouchakour, Z. Laid, L. Zaghba: Comparative Study of P\&O and Fuzzy MPPT Controllers and

Their Optimization Using PSO and GA to Improve Wind Energy System

[6] A. Bouchakour, A. Borni, M. Brahami, Comparative study of P\&O-PI and fuzzy-PI MPPT controllers and their optimisation using GA and PSO for photovoltaic water pumping systems, International Journal of Ambient Energy, Vol. 42, No. 15, pp. 1746-1757, 2021. https://doi.org/10.1080/01430750.2019.1614988

[7] A. Jubaer, S. Zainal, An improved perturb and observe (P\&O) maximum power point tracking (MPPT) algorithm for higher efficiency, Applied Energy, Vol. 150, pp. 97-108, 2015. https://doi.org/10.1016/j.apenergy.2015.04.006

[8] S. Biricik, H. Komurcugil, Proportional-Integral and Proportional-Resonant Based Control Strategy for PUC Inverters, IEEE, 2018.

https://doi.org/10.1109/IECON.2018.8591371

[9] V-T. Phan, H-H. Lee, T-W. Chun, An Improved Control Strategy Using a PI-Resonant Controller for an Unbalanced Stand-Alone Doubly-Fed Induction Generator, Journal of Power Electronics, Vol. 10, No. 2, pp. 194-202, 2010.

https://doi.org/10.6113/JPE.2010.10.2.194

[10] Z. Civelek, M. Lüy, E. Çam, H. Mamur, A new fuzzy logic proportional controller approach applied to individual pitch angle for wind turbine load mitigation, Renewable Energy, Vol. 111, pp. 708-717, 2017. https://doi.org/10.1016/j.renene.2017.04.064

[11] A. Borni, A. Bouchakour, N. Bessous, T. Abdelkrim, A. Lakhdari, L. Zaghba, Optimization of the fuzzy MPPT controller by GA for the single-phase grid-connected photovoltaic system controlled by sliding mode, AIP Conference Proceedings, Vol. 2190, No. 1, 020003, 2019. https://doi.org/10.1063/1.5138489

[12] C. ed-dahmani, H. Mahmoudi, A Comparative Study of Fuzzy Logic Controllers for Wind Turbine Based on PMSG, International Journal of Renewable Energy Research, Vol. 8, No. 3, pp. 1386-1392, 2018.

[13] C. Bhattacharjee, B.K. Roy, Advanced fuzzy power extraction control of wind energy conversion system for power quality improvement in a grid tied hybrid generation system, IET Generation, Transmission \& Distribution, Vol. 10, No. 5, pp. 1179-1189, 2016. https://doi.org/10.1049/iet-gtd.2015.0769

[14] H.M. Yassin, H.H. Hanafy, M.M. Hallouda, Enhancement low-voltage ride through capability of permanent magnet synchronous generator-based wind turbines using interval type-2 fuzzy control, IET Renewable Power Generation, Vol. 10, No. 3, pp. 339348, 2016. https://doi.org/10.1049/iet-rpg.2014.0453

[15] S.K. Rechkemmer, R. Izumi, W. Zhang, O. Sawodny, Estimation of Permanent Magnet Synchronous Machine Performance for Pre-Design Using a Reluctance Network, IFACPapers On Line, Vol. 51, No. 31, pp. 75-80, 2018.

https://doi.org/10.1016/j.ifacol.2018.10.015

[16] Y. Yang, Q. He, C. Fu, S. Liao, P. Tan, Efficiency improvement of permanent magnet synchronous motor for electric vehicles, Energy, Elsevier, Vol. 213, 2020.

https://doi.org/10.1016/j.energy.2020.118859

[17] C.H. Lin, C.P. Lin, Voltage Control of PM Synchronous Motor Driven PM Synchronous Generator System Using Recurrent Wavelet Neural Network Controller, Journal of Applied Research and Technology, Vol. 11, No. 2, pp. 183-194, 2013.

https://doi.org/10.1016/S1665-6423(13)71528-1 
A. Borni, M. Bechouat, N. Bessous, A. Bouchakour, Z. Laid, L. Zaghba: Comparative Study of P\&O and Fuzzy MPPT Controllers and

Their Optimization Using PSO and GA to Improve Wind Energy System

[18] J.C. Rosas-Caro, J.C. Mayo-Maldonado, A. Valderrabano-Gonzalez, F. Beltran-Carbajal, J.M. Ramirez-Arredondo, J.R. Rodriguez-Rodriguez, DC-DC multiplier boost converter with resonant switching, Electric Power Systems Research, Vol. 119, pp. 83-90, 2015.

https://doi.org/10.1016/j.epsr.2014.09.003

[19] B. Alharbi, M. Alhomim, R. McCann, Robust Control of DC-DC Boost Converter by using $\mu$ Synthesis Approach, IFAC-Papers On Line, Vol. 52, No. 4, pp. 200-205, 2019.

https://doi.org/10.1016/j.ifacol.2019.08.261

[20] A. Sapena-Bano, J. Martinez-Roman, R. Puche-Panadero, M. Pineda-Sanchez, J. PerezCruz, M. Riera-Guasp, Induction machine model with space harmonics for the diagnosis of rotor eccentricity, based on the convolution theorem, International Journal of Electrical Power \& Energy Systems, Vol. 117, 2020.

https://doi.org/10.1016/j.ijepes.2019.105625

[21] R. Kumar, S. Das, A. Bhaumik, Speed sensorless model predictive current control of doubly-fed induction machine drive using model reference adaptive system, ISA Transactions, Vol. 86, pp. 215-226, 2019. https://doi.org/10.1016/j.isatra.2018.10.025

[22] C.A. Macana, H.R. Pota, M.A. Hossain, Modeling and Simulation of Inverter based Distributed Generators for Renewable Energy Integration, IFAC-Papers On Line, Vol. 52, No. 4, pp. 30-35, 2019. https://doi.org/10.1016/j.ifacol.2019.08.150

[23] S.P. Bihari, P.K. Sadhu, Design analysis of high level inverter with EANFIS controller for grid connected PV system, Analog Integrated Circuits and Signal Processing, Vol. 103, pp. 411-424, 2020. https://doi.org/10.1007/s10470-019-01578-9

[24] Md. Rabiul Islam, A. M. Mahfuz-Ur-Rahman, Md. Mazharul Islam, Youguang G. Guo, Jianguo G. Zhu, Modular Medium-Voltage Grid-Connected Converter With Improved Switching Techniques for Solar Photovoltaic Systems, IEEE Transactions on Industrial Electronics, Vol. 64, No. 11, 2017. https://doi.org/10.1109/TIE.2017.2652402

[25] L. Fan, L. Zhang, An Improved Vector Control of an Induction Motor based on Flatness, Procedia Engineering, Vol. 15, pp. 624-628, 2011.

https://doi.org/10.1016/i.proeng.2011.08.116

[26] M. Arrouf, N. Bouguechal, Vector control of an induction motor fed by a photovoltaic generator, Applied Energy, Vol. 74, No. 1-2, pp. 159-167, 2003.

https://doi.org/10.1016/S0306-2619(02)00142-3

[27] H-C. Chuang, G-D. Li, C-T. Lee, The efficiency improvement of AC induction motor with constant frequency technology, Energy, Elsevier, Vol. 174, pp. 805-813, 2011.

https://doi.org/10.1016/j.energy.2019.03.019

[28] M.P. Sruthi, C. Nagamani, G. Saravana Ilango, An improved algorithm for direct computation of optimal voltage and frequency for induction motors, Engineering Science and Technology, an International Journal, Vol. 20, No. 5, pp. 1439-1449, 2017.

https://doi.org/10.1016/j.jestch.2017.11.007

[29] A. Bouchakour, A. Borni, S.E. Boukebbous, L. Zaghba, A. Fezzani, M. Brahami, Comparative Study on Photovoltaic Water Pumping Systems Driven by Direct Current Motor (DCM) and Induction Motor (IM) Optimized with P\&O Control, AIP Conference Proceedings, Vol. 2190, No. 1, 020002, 2019. https://doi.org/10.1063/1.5138488 
A. Borni, M. Bechouat, N. Bessous, A. Bouchakour, Z. Laid, L. Zaghba: Comparative Study of P\&O and Fuzzy MPPT Controllers and

Their Optimization Using PSO and GA to Improve Wind Energy System

[30] T. Khatib, D. Muhsen, Photovoltaic Water Pumping Systems, Concept, Design, and Methods of Optimization, $1^{\text {st }}$ Edition, $30^{\text {th }}$ October 2020.

[31] A-R. Youssef, A.I.M. Ali, M.S.R. Saeed, E.E.M. Mohamed, Advanced multi-sector P\&O maximum power point tracking technique for wind energy conversion system, International Journal of Electrical Power \& Energy Systems, Vol. 107, pp. 89-97, 2019. https://doi.org/10.1016/j.ijepes.2018.10.034

[32] J. Ahmed, Z. Salam, An improved perturb and observe (P\&O) maximum power point tracking (MPPT) algorithm for higher efficiency, Applied Energy, Vol. 150, pp. 97-108, 2015. https://doi.org/10.1016/j.apenergy.2015.04.006

[33] M. Bendaoud, S. Ladide, A. El Fathi, H. Hihi, K. Faitah, Fuzzy logic peak current control strategy for extracting maximum power of small wind power generators, International Transactions on Electrical Energy Systems, Vol. 29, No. 2, 2018.

https://doi.org/10.1002/etep.2730

[34] Hussain Attia, Fuzzy Logic Controller Effectiveness Evaluation through Comparative Memberships for Photovoltaic Maximum Power Point Tracking Function, International Journal of Power Electronics and Drive System, Vol. 9, No. 3, pp. 1147-1156, 2018.

https://doi.org/10.11591/ijpeds.v9.i3.pp1147-1156

[35] S. Miqoi, A. El Ougli, M. Boutouba, B. Tidhaf, Fuzzy sliding mode control for maximum power point tracking of a photovoltaic pumping system, Journal of Electrical Systems, Vol. 13, No. 1, pp. 95-114, 2017.

[36] J. Kennedy, R. Eberhart, Particle Swarm Optimization, in Proceedings of ICNN'95 International Conference on Neural Networks, 2020.

https://doi.org/10.1109/ICNN.1995.488968

[37] H.M.H. Farh, A.M. Eltamaly, A.B. Ibrahim, M.F. Othman, M.S. Al-Saud, Dynamic global power extraction from partially shaded photovoltaic using deep recurrent neural network and improved PSO techniques, International Transactions on Electrical Energy Systems, Vol. 29, No. 9, 2019. https://doi.org/10.1002/2050-7038.12061

[38] A. Harrag, S. Messalti, PSO based SMC variable step size P\&O MPPT controller for PV systems under fast changing atmospheric conditions, International Journal of Numerical Modelling, Vol. 32, No. 5, 2019. https://doi.org/10.1002/jnm.2603

[39] B. Liu, J. Li, W. Lin, W. Bai, P. Li, Q. Gao, K-PSO: An improved PSO-based container scheduling algorithm for big data applications, International Journal of Network Management, Vol. 31, No. 2, 2020. https://doi.org/10.1002/nem.2092

[40] V. Devasahayam, M. Veluchamy, An enhanced ACO and PSO based fault identification and rectification approaches for FACTS devices, International Transactions on Electrical Energy Systems, Vol. 27, No. 8, 2017.

https://doi.org/10.1002/etep.2344

[41] X. Jua, F. Liu, L. Wang, W-J. Lee, Wind farm layout optimization based on support vector regression guided genetic algorithm with consideration of participation among landowners, Energy Conversion and Management, Vol. 196, pp. 1267-1281, 2019. https://doi.org/10.1016/j.enconman.2019.06.082 
[42] A.Z. Dhunny, D.S. Timmons, Z. Allam, M.R. Lollchund, T.S.M. Cunden, An economic assessment of near-shore wind farm development usinga weather research forecastbased genetic algorithm model, Energy, Elsevier, Vol. 201, 2020.

https://doi.org/10.1016/j.energy.2020.117541 